\title{
The effects of low dose intravenous 99-126 atrial natriuretic factor infusion in patients with chronic renal failure
}

\author{
A.S. Woolf, M.A. Mansell' ${ }^{1}$ B.I. Hoffbrand, S.L. Cohen² and P.J.A. Moult
}

The Academic Unit of Endocrinology and Diabetes and Unit of Medicine, Whittington Hospital, London N19 5NF, 을 ${ }^{1}$ St Peter's Hospitals and Institute of Urology, London WC2, and ${ }^{2}$ University College Hospital, London WCIE, UK

\begin{abstract}
Summary: The aim was to study the renal and hormonal effects of intravenous 99-126 atrial natriuretic factor (ANF) infusion in a mixed group of patients who had moderate to severe chronic renal failure (CRF) and who were not treated with dialysis. The peak mean plasma level of ANF achieved during the experiment was at the upper limit of an absolute range of basal values previously recorded in a larger group of patients with similar degrees of renal impairment. A significant tissue effect was confirmed by rises in plasma and urinary cyclic guanosine monophosphate, the 'second-messenger' of ANF. ANF infusion increased sodium excretion rate by a mean of $68 \%$ compared with a fall of $40 \%$ in a placebo group, and significant increases in urinary albumin excretion occurred during the peptide infusion. Thus, the high levels of plasma ANF found in CRF may have a role in the maintenance of sodium balance. In addition, the proteinuric effect may be detrimental to long-term renal function.
\end{abstract}

\section{Introduction}

Sodium balance is maintained in chronic renal failure (CRF) by an increase in fractional excretion of sodium, and it has been suggested that this effect is mediated by an unidentified circulating natriuretic agent. ${ }^{1,2}$ Recently, atrial natriuretic factor (ANF) has been implicated as an important hormone in the control of plasma volume. In healthy subjects, ANF is released by the heart in response to blood volume expansion, ${ }^{3}$ and low dose intravenous infusion causes a significant natriuresis. ${ }^{4,5}$ Cyclic guanosine monophosphate (cGMP) may act as a 'second messenger' to ANF, and extracellular levels of the nucleotide may act as a guide to the tissue action of ANF. ${ }^{6}$

Plasma immunoreactive ANF values are often raised in patients with CRF who do not require dialysis, ${ }^{7,8}$ and this may be due to a combination of volume overload, decreased renal excretion of the peptide together with the frequent occurrence of cardiac disease in this population. However, the biological effects of these high levels are unknown. In order to study the role of ANF in this disorder we have followed the renal and hormonal effects of intravenous ANF infusion.

\section{Patients and methods}

After approval by the Department of Health and the hospitals' ethical committees, 15 patients with stable

Correspondence: P.J.A. Moult, M.D., F.R.C.P.

Accepted: 21 January 1989
CRF were recruited from nephrology clinics, and they gave informed consent. None had valvular heart ${ }^{\Phi}$ disease, a history of cardiac ischaemia, nephrotic $\overrightarrow{0}$ syndrome or peripheral oedema. They were assignede alternately to have either an ANF or placebo infusion. The active group ( $n=8,5$ males), had diagnoses 물 glomerulonephritis (3), chronic interstitial disease (3), hypertension (1) and adult polycystic disease (1). The placebo group ( $n=7,3$ males) had diagnoses of glomerulonephritis (2), chronic interstitial disease (4) and hypertension (1). One patient in each group took음 their regular nifedipine on the study day, and one subject in each group stopped a thiazide and betablockade two days before the study. Dietary sodium was uncontrolled but the two groups had similaro urinary sodium excretion on the day before the experiment (active group, mean \pm s.e.m.: $127 \pm 23 \mathrm{mmol}$ and placebo group: $145 \pm 23 \mathrm{mmol}$ ). The daily protein excretion of the active group was $1.27 \pm 0.30 \mathrm{~g}$, and of the placebo group was $1.05 \pm 0.33 \mathrm{~g}$.

On the study day they ate a light breakfast which did $\frac{7}{2}$ not include meat. From $0900-1400 \mathrm{~h}$ they sat with legs dependent, rising briefly to pass urine every o 30 minutes. Between 0900-0930 h they each drank 1 litre of water, and took $200 \mathrm{ml}$ half-hourly thereafter. At $0900 \mathrm{~h}$, sodium aminohippurate (Merck, $\sigma$ Sharp and Dohme) and inulin (Laevosan Interna-? tional) were infused via a forearm vein, to achieve plasma levels of $20 \mathrm{mg} / \mathrm{l}$ and $250 \mathrm{mg} / \mathrm{l}$ respectively and $\stackrel{\Phi}{\Phi}$ continued for 5 hours. After an equilibration hour, + and a further control hour, $50 \mu \mathrm{g}$ of ANF 99-126

(C) The Fellowship of Postgraduate Medicine, $1989 \frac{\mathbb{Q}}{\mathbb{Q}}$ 
(Bissendorf Peptide) dissolved in $100 \mathrm{ml} 0.9 \%$ saline was administered between 1100 and $1300 \mathrm{~h}$ into the same vein (an average rate of $1.8 \mathrm{pmol} / \mathrm{kg} / \mathrm{min}$ ). For the placebo infusions, only saline was given. Blood was drawn from the opposite arm at the midpoint of each urine collection. The final hour between 1300 and $1400 \mathrm{~h}$ served as a recovery hour.

ANF was measured by radioimmunoassay (RIA) using a polyclonal antibody (Peninsula Laboratories) directed to the biologically active carboxy-terminal of 99-126 ANF. The peptide was extracted from the plasma using octadecylsilica, and the recovery of ANF added to plasma was $70 \pm 5 \%$ (mean \pm s.d.). The minimum detectable plasma level was $1 \mathrm{pmol} / \mathrm{l}$, and the coefficient of variation of the RIA was $10 \% .{ }^{9}$ Healthy plasma contains two components of the ANF 126 amino-acid prohormone, namely the $1-98$ and 99-126 molecules. ${ }^{10}$ Chromatography of uraemic plasma shows that 99-126 ANF is the major circulating immunoreactive C-terminal component of the propeptide, although a low concentration of an antiparallel dimer of $99-126$ can also be identified. ${ }^{10}$ Antisera directed to the carboxy-terminal of 99-126 ANF may cross-react with this larger molecule ${ }^{11}$ so that the basal immunoreactive ANF measured in this study may be a slight overestimate of true 99-126 ANF values. Although we have not performed chromatograms of plasma extracts from our patients, serial dilutions parallel the 99-126 ANF standard curve, suggesting that the measured immunoreactive ANF corresponded to the 99-126 molecule. Healthy, sitting plasma 99-126 ANF $(n=24)$ in our laboratory was (mean \pm s.e.m.) $6.9 \pm 0.8 \mathrm{pmol} / \mathrm{l}$.

Plasma renin activity (PRA) was measured by RIA of angiotensin I generated by plasma incubation at $37^{\circ} \mathrm{C} .^{9}$ The healthy mean \pm s.e.m. of 18 adults was $1.21 \pm 0.16 \mathrm{nmol} / \mathrm{h} / \mathrm{l}$. Plasma aldosterone was measured by a commercial RIA (CIS) after plasma extraction. ${ }^{12}$ The healthy mean \pm s.e.m. of 18 adults was $258 \pm 67 \mathrm{pmol} / \mathrm{l}$. Cyclic GMP was measured by RIA, ${ }^{5}$ and the healthy plasma mean \pm s.e.m. of 18 adults was $1.6 \pm 0.2 \mathrm{nmol} / \mathrm{l}$. Urinary albumin was measured with a commercial RIA (Pharmacia).

Sodium and potassium were measured by flame photometer and plasma albumin by the bromocresol green method. Inulin and PAH clearances were taken to equal the glomerular filtration rate (GFR) and effective renal plasma flow (ERPF) respectively. No correction was made for tubular extraction efficiency of PAH which was unknown in these patients. One observer measured the blood pressure with a mercury sphygmomanometer every 30 minutes.

Unless otherwise stated results are given as mean \pm s.e.m. Because of the wide variation between subjects in basal GFR, sodium and albumin excretion, these responses were expressed as percentages of the values found during the half-hour basal period immediately before the start of the ANF or placebo infusion. Student's unpaired $t$-tests were applied between mean active and placebo values at each time point, and upon the difference in incremental areas following the second basal sample. Significance was determined at the 1:20 level.

\section{Results}

Basal values in the two groups were similar and are shown in Table I. Significant differences at identical time points are shown in Figure 1, and significant differences in incremental areas are identified in the text.

During the active infusion the mean plasma ANF rose four-fold, and rapidly returned to basal levels in the recovery hour. Basal plasma cGMP was elevated compared to healthy subjects, and in the active group the mean level increased two-fold. Despite a rise of absolute urinary cGMP excretion from $140 \pm 30$ to $396 \pm 87 \mathrm{pmol} / \mathrm{min}$, the fractional excretion of the nucleotide did not change significantly (from $115 \pm 19$ to $104 \pm 9 \%$ ). The incremental areas for plasma ANF, cGMP and urinary cGMP were significantly greater in the active versus the placebo groups (all $P<0.01$ ).

Plasma aldosterone tended to fall during the ANF infusion, and then rose in the recovery hour. Plasma aldosterone was constant in the placebo study but the difference between groups was not significant. PRA showed a tendency to fall throughout the study in both groups.

In the active group the mean GFR tended to rise but the individual absolute increments were highly variable, ranging from $2-20 \mathrm{ml} / \mathrm{min}$. However, the difference of incremental areas of the two groups failed to reach significance $(P=0.07)$. ERPF was constant in both groups.

In the active group urinary sodium increased slowly to reach a peak of $168 \pm 20 \%$ of basal values in the final half-hour of the ANF infusion, and by the end of the recovery hour had returned to basal values. In this small group, there was no relation between the absolute rise in sodium excretion rate and the initial GFR. Compared to placebos, there was a highly significant increase in incremental area $(P<0.001)$. During the ANF infusion, fractional excretion of sodium tended to rise and then it fell rapidly in the recovery hour to $50 \%$ of basal values. In contrast, in the placebo group, there was a steady fall throughout the experiment of both absolute and fractional sodium excretion. Urine potassium excretion remained constant in both groups.

In the active group urinary albumin excretion rate increased in all patients to a peak mean of $280 \pm 110 \%$ of basal values during the second hour of the ANF infusion, and then returned to basal values in the 
Table I Basal values

\begin{tabular}{|c|c|c|}
\hline & Active group $(n=8)$ & Placebo group $(n=7)$ \\
\hline Age (years) & $40 \pm 4$ & $41 \pm 5$ \\
\hline Mean BP $(\mathrm{mmHg})$ & $96 \pm 4$ & $97 \pm 7$ \\
\hline Pulse (bpm) & $64 \pm 6$ & $62 \pm 2$ \\
\hline \multicolumn{3}{|l|}{ Plasma indices } \\
\hline Sodium $(\mathrm{mmol} / \mathrm{l})$ & $136 \pm 1$ & $134 \pm 1$ \\
\hline Potassium (mmol/l) & $4.5 \pm 0.2$ & $4.5 \pm 0.3$ \\
\hline Creatinine $(\mu \mathrm{mol} / \mathrm{l})$ & $472 \pm 100$ & $398 \pm 86$ \\
\hline Albumin $(\mathrm{g} / \mathrm{l})$ & $40.1 \pm 1.7$ & $40.9 \pm 1.0$ \\
\hline ANF (pmol/l) & $9.6 \pm 2.1$ & $10.6 \pm 1.8$ \\
\hline PRA (nmol/l) & $1.24 \pm 0.34$ & $1.36 \pm 0.59$ \\
\hline Aldosterone $(\mathrm{pmol} / \mathrm{l})$ & $1595 \pm 500$ & $1207 \pm 425$ \\
\hline Cyclic GMP (nmol/l) & $7.0 \pm 1.4$ & $6.4 \pm 1.3$ \\
\hline \multicolumn{3}{|l|}{ Urine indices } \\
\hline Cyclic GMP (pmol/min) & $140 \pm 30$ & $167 \pm 44$ \\
\hline GFR $\left(\mathrm{ml} / \mathrm{min} / 1.73 \mathrm{~m}^{2}\right)$ & $13.5(8.3-52.4)$ & $23.3(13.3-45.1)$ \\
\hline $\operatorname{ERPF}\left(\mathrm{ml} / \mathrm{min} / 1.73 \mathrm{~m}^{2}\right)$ & $30(20-176)$ & $88(23-157)$ \\
\hline Volume $(\mathrm{ml} / \mathrm{min})$ & $4.4 \pm 0.8$ & $4.0 \pm 0.7$ \\
\hline Sodium $(\mu \mathrm{mol} / \mathrm{min})$ & $115(44-408)$ & $179(77-224)$ \\
\hline Sodium ( $\%$ GFR) & $5.62 \pm 1.06$ & $6.13 \pm 1.66$ \\
\hline Potassium $(\mu \mathrm{mol} / \mathrm{min})$ & $51 \pm 5$ & $47 \pm 8$ \\
\hline Albumin $(\mu \mathrm{g} / \mathrm{min})$ & $575(70-1612)$ & $385(120-1610)$ \\
\hline Albumin (\% GFR) & $0.054(0.003-0.406)$ & $0.045(0.006-0.195)$ \\
\hline
\end{tabular}

Basal data are given as mean \pm s.e.m., unless distribution is non-Gaussian, when values are median (range).

recovery hour. The incremental area was significantly greater than in placebos $(P=0.02)$.

In both groups blood pressure, pulse, plasma electrolytes and plasma albumin were constant. No patient experienced any side effects during either the ANF or placebo infusions.

\section{Discussion}

The peak mean plasma value of ANF during the peptide infusion was just above the upper limit of a range of basal levels $(1.0-39.0 \mathrm{pmol} / \mathrm{l})$ measured by our laboratory in a larger group of patients with CRF $(n=36)$ of a similar age and degree of renal impairment. ${ }^{8}$ This rise of ANF caused a significant tissue effect as judged by the increases of plasma and urinary cGMP. ${ }^{6}$ At all time periods, in both groups, the ratio of cGMP to inulin clearance was unity and we were unable to detect any nephrogenous nucleotide, confirming previous observations in healthy subjects. ${ }^{13}$ Arterial walls are rich in ANF receptors and may contribute the majority of both plasma and urinary cGMP. ${ }^{6}$ Therefore, urinary cGMP is unlikely to be a marker for the specific renal effects of ANF.

The increase in sodium excretion in the active group contrasted with the fall which occurred in the placeb group. A similar fall has been recorded in anothef study, and as a group patients with CRF excrete mos sodium at night. ${ }^{14}$ The ANF-induced natriuresis sug gests that the raised levels of plasma peptide found io some patients with $\mathrm{CRF}^{7,8}$ may contribute to sodium balance in this disorder. Although plasma ANF rises in animals with CRF when dietary salt is increased, $\frac{15}{5}$ further studies are required in patients to determine whether the four-fold rise in ANF that we recorded io the active group is compatible with a change caused b dietary sodium loading.

When pharmacological doses of ANF are administered to rats with CRF both sodium excretion and GFR are reported to rise. ${ }^{16}$ However, we failed to find a major rise in GFR in our patients. Moreove low-dose ANF administered to healthy subjects pro duces natriuresis without a significant rise in filtratio rate. ${ }^{4,5}$ Therefore, the importance of a rise in GFR in the ANF-induced natriuresis remains uncertain.

An increase of albuminuria has been recorded aftes administration of pharmacological doses of ANF to healthy subjects, ${ }^{17}$ and during infusion into patient席 with the nephrotic syndrome. ${ }^{5,18}$ When phar macological doses of ANF are administered to animals, both the glomerular capillary hydraulic prese 


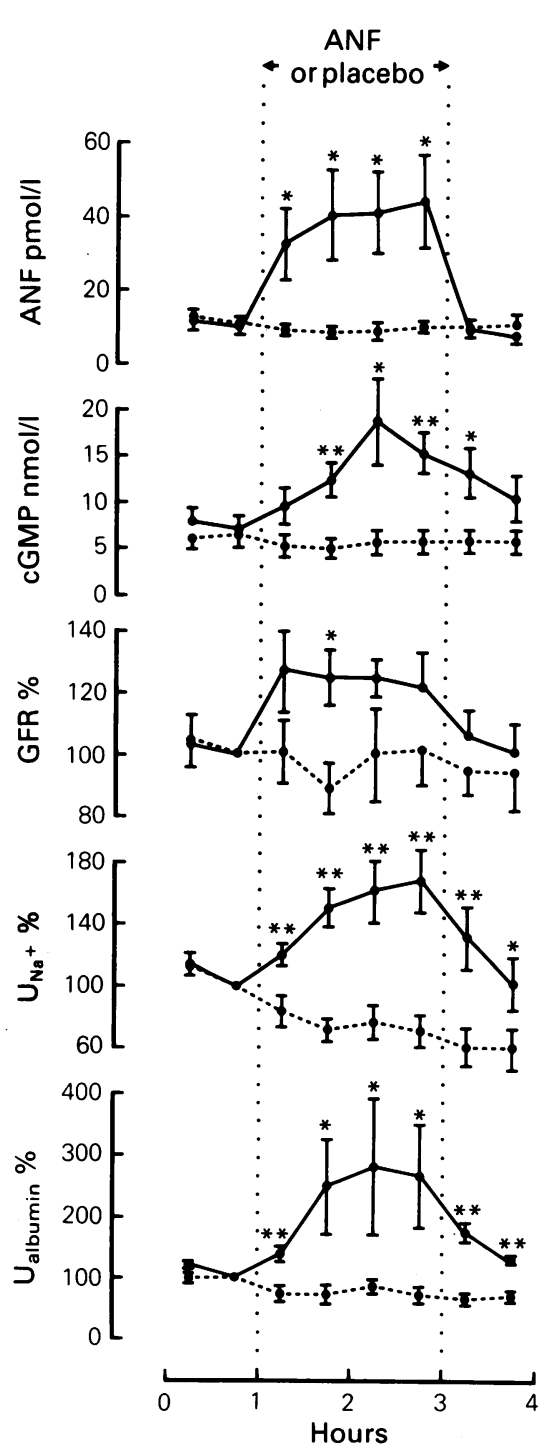

Figure 1 Mean \pm s.e.m. values of plasma ANF, plasma cyclic GMP, GFR, urinary sodium excretion $\left(\mathrm{U}_{\mathrm{Na}^{+}}\right)$and urinary albumin excretion $\left(U_{\text {albumin }}\right)$. Data for GFR and urinary excretions are plotted at the midpoint of each half hour period and are expressed as percentages of the second basal collection. Solid lines represent the active group and short dashes represent the separate placebo group. The asterisks indicate a significant difference between means of each group at each time point. ${ }^{*} P<0.05$ and ${ }^{* *} P<0.01$. sure and permeability of the glomerular barrier increase, ${ }^{19}$ and similar mechanisms could have contributed to the rise in albumin excretion in the studies described above.

In patients with chronic glomerulonephritis and pyelonephritis the degree of proteinuria is a marker for the rate of renal deterioration. ${ }^{20}$ As well as indicating the severity of glomerular structural and functional changes, the enhanced passage of macromolecules across the glomerulus may cause further structural damage. ${ }^{21}$ In animals with partial renal ablation ${ }^{22}$ and humans with a variety of primary renal diseases ${ }^{23}$ the control of arterial hypertension can reduce proteinuria and stabilize renal function, an effect that may be mediated by the lowering of glomerular capillary pressure in surviving nephrons. ${ }^{22}$

In patients with CRF there is a positive correlation between plasma ANF and arterial blood pressure, ${ }^{7,8}$ and this may reflect a partial dependence of blood pressure on blood volume. ${ }^{24}$ It is interesting to speculate that in some patients with CRF, the retention of sodium may lead to both systemic arterial hypertension and a rise of plasma ANF. Both of these changes may then not only serve the homeostatic function of increasing urinary sodium excretion, but could also alter glomerular haemodynamics and increase proteinuria to the detriment of long-term renal function.

\section{Acknowledgements}

The work was supported by the North East Thames Regional Health Authority Locally Organised Research Scheme and the Rockefeller Trust. 


\section{References}

1. Slatopolsky, E., Elkan, I.O., Weerts, C. \& Bricker, N Studies on the characteristics of the control system governing sodium excretion in uremic man. J Clin Invest 1968, 47: 521-530.

2. Fine, L.G., Bourgoignie, J.J., Hwang, K.H. \& Bricker, N.S. On the influence of the natriuretic factor from patients with chronic uremia on the bioelectric properties and sodium transport of the isolated mammalian collecting tubule. J Clin Invest 1976, 58: 590-597.

3. Sagnella, G.A., Markandu, N.D., Shore, A.C. \& MacGregor, G.A. Effects of changes in dietary sodium intake and saline infusion on immunoreactive atrial natriuretic peptide in human plasma. Lancet 1985, ii: $1208-1211$.

4. Richards, A.M., Tonolo, G., Montorsi, P. et al. Low dose infusions of 26- and 28-amino acid human atrial natriuretic peptides in normal man. $J$ Clin Endocrinol Metab 1988, 66: 465-473.

5. Woolf, A.S., Lyon, T.L., Hoffbrand, B.I., Cohen, S.L. \& Moult, P.J.A. The effects of physiological infusion of atrial natriuretic factor in healthy subjects and patients with the nephrotic syndrome. Nephron (in press).

6. Gerzer, R., Weil, J., Strom, T. \& Muller, T. Mechanisms of action of atrial natriuretic factor. Klin Wochenschr 1986, 64 (Suppl V1): 21-26.

7. Hasegawa, K., Matsushita, Y., Inoue, T., Morii, H., Ishibashi, M. \& Yamaji, T. Plasma levels of atrial natriuretic peptide in patients with chronic renal failure. $J$ Clin Endocrinol Metab 1986, 63: 819-822.

8. Woolf, A.S., Kingswood, J.C., Kumar, A., Lyon, T.L., Mansell, M.A. \& Moult, P.J.A. Determinants of plasma atrial natriuretic factor in chronic renal failure. Clin Sci 1988, 75 (Suppl 19): 48pp.

9. Woolf, A.S. \& Moult, P.J.A. Plasma levels of atrial natriuretic peptide in hyperthyroidism. Clin Endocrinol 1987, 27: 721-725.

10. Itoh, H., Nakao, K., Sugawara, A. et al. Gamma atrial natriuretic polypeptide (gamma ANP)-derived peptides in human plasma: Cosecretion of $\mathrm{N}$-terminal gamma ANP fragment and alpha ANP. J Clin Endocrinol Metab 1988, 67: 429-437.

11. Itoh, H., Nakao, K., Mukoyama, M. et al. Effects of intravenously administered Beta-human atrial natriuretic polypeptide in humans. Hypertension 1988, 11: 697-702.

12. Jones, J.C., Carter, G.D. \& MacGregor, G.A. Interference by polar metabolites in a direct radioimmunoassay for plasma aldosterone. Ann Clin Biochem 1981, 18: 54-59.
13. Broadus, A.E., Kaminsky, N.I., Hardman, J.G., Suthere land, E.W. \& Liddle, G.W. Kinetic parameters and rena市 clearances of plasma adenosine $3^{\prime}, 5^{\prime}$-monophosphate and guanosine $3^{\prime}, 5^{\prime}$-monophosphate in man. $J$ Clin: Invest 1970, 49: 2222-2236.

14. Hillier, P., Knapp, M.S. \& Cove-Smith, R. Circadian variations in urine excretion in chronic renal failure. $Q$ Med 1980, XLIX: $461-478$.

15. Smith, S., Anderson, S., Ballerman, B.J. \& Brenners B.M. Role of atrial natriuretic peptide in adaptation o\$ sodium excretion with reduced renal mass. J Clin Invesw 1986, 77: 1395-1398.

16. Cole, B.R., Kuhnline, M.A. \& Needleman, P. Atriopep $\overrightarrow{0}$ tin III. A potent natriuretic, diuretic, and hypotensive agent in rats with chronic renal failure. J Clin Invest $1985 \mathrm{w}$ 76: $2413-2415$.

17. McMurray, J., Struthers, A.D., Seidelin, P.H. \& Howeso J.E.A. The effect of ANF on urinary protein excretion man. Clin Sci 1988, 75 (Suppl 19): 47pp.

18. Zietse, R. \& Schalekamp, M.A. Effect of synthetic ANR (102-126) in nephrotic syndrome. Kidney Int 1988, 34 717-724.

19. Fried, T.A., McCoy, R.N., Osgood, R.W. \& Stein, J.H Effect of atriopeptin II on determinants of glomerulao filtration rate in the in vitro perfused dog glomerulus. $A \vec{m}$ J Physiol 1986, 250: F1119-1122.

20. Williams, P.S., Fass, G. \& Bone, J.M. Renal patholog and proteinuria determine progression in untreate $\Phi$ mild/moderate chronic renal failure. $Q J \mathrm{Med} 1988,252{ }^{\circ}$ $343-454$.

21. Couser, W.G. \& Stilmant, M.M. Mesangial lesions gुnd focal glomerular sclerosis in the aging rat. Laboration Investigation 1975, 33: 491-501.

22. Meyer, T.W., Anderson, S., Rennke, H.G. \& Brenner B.M. Reversing glomerular hypertension stabilise established glomerular injury in renal ablation. Hypertens 1986, 4 (Suppl 5): S239-S241.

23. Alvestrand, A., Gutierrez, A., Bucht, H. \& Bergstrom, $\overrightarrow{\bar{b}}$ Reduction of blood pressure retards progression of chronic renal failure in man. Nephrol Dial Transplan 1988, 3: 624-631.

24. Tarazi, R.C., Dustan, H.P., Frohlich, E.D., Giffor क्षि R.W. \& Hoffman, G.C. Plasma volume and chroniç hypertension. Arch Intern Med 1970, 125: 835-842. 